Article

\title{
Flame Retardance and Smoke Suppression of CFA/APP/LDHs/EVA Composite
}

\author{
Lili Wang, Miaojun Xu, Baoli Shi and Bin Li * \\ Heilongjiang Key Laboratory of Molecular Design and Preparation of Flame retarded Materials, \\ College of Science, Northeast Forestry University, Harbin 150040, China; liliwangsh@gmail.com (L.W.); \\ miaojunxu@163.com (M.X.); shi_baoli@yahoo.com (B.S.) \\ * Correspondence: rainkiss1014@163.com; Tel.: +86-451-8219-2699
}

Academic Editor: Stefano Invernizzi

Received: 24 May 2016; Accepted: 5 September 2016; Published: 9 September 2016

\begin{abstract}
A new intumescent flame-retardants (IFR) system including the charing-foaming agent (CFA), ammonium polyphosphate (APP) and modified-layered double hydroxides (LDHs) with different transition metals $(\mathrm{Ni}, \mathrm{Co}, \mathrm{Cu})$ were used in the ethylene vinyl acetate (EVA) matrix. Both the limiting oxygen index and the vertical burning tests indicate that the CFA/APP system and LDHs have significant synergistic flame retardant effects. The morphology of combustion residues indicates that the many pores of residues can prevent the melt dripping. The thermal analysis shows that the flame retardants obviously enhanced the thermal degradation temperature of ethylene-based chains of the composites. The cone calorimeter test reveals that the $\mathrm{CO}_{2}$ and combustion residues have an important influence on the reduction of heat release rate (HRR), the smoke production rate (SPR), the production rate and the mean release yield of $\mathrm{CO}$. The composite containing $\mathrm{Cu}$ (ELDH-Cu) delivers an $82 \%$ reduction in peak heat release rate, while ELDH-Ni has the best CO suppression among all composites. This work not only confirms the flame retardance and smoke suppression of CFA/APP/LDH/EVA, but also provides an effective method for producing new flame retardants and smoke suppressants.
\end{abstract}

Keywords: composite; layered double hydroxides; flame retardant mechanism; production rate of $\mathrm{CO}_{2}$; mean release yield of $\mathrm{CO}_{2}$

\section{Introduction}

The ethylene vinyl acetate (EVA) polymer is widely used as an insulator for wires and cables. However, the EVA not only is easily flammable, but also releases the toxic $\mathrm{CO}$ gas during combustion [1,2]. To reduce flammability and the release of CO for EVA, the addition of flame retardants is effective [3,4]. Brominated flame retardants are the most effective and show a good ratio of property to price, however, their uses have been limited to the consideration of life safety and environmental problems due to a large amount of smoke and hydrogen bromide produced during burning $[5,6]$. The layered double hydroxides (LDHs) is a large class of anionic clays with a general formula of $\left[\mathrm{M}^{2+}{ }_{1-x} \mathrm{M}^{3+}{ }_{x}(\mathrm{OH})_{2}\right]^{x+}\left[\mathrm{A}^{n-}\right]_{x / n} \cdot m \mathrm{H}_{2} \mathrm{O}$, where $\mathrm{M}^{2+}$ and $\mathrm{M}^{3+}$ are divalent and trivalent metal cations, $x=\mathrm{M}^{3+} /\left(\mathrm{M}^{2+}+\mathrm{M}^{3+}\right)$ molar ratio and $\mathrm{A}^{n-}$ is an $n^{-}$valent interlayer anion $[7,8]$. During combustion, LDHs lose the adsorbed water and interlayer water, which can dilute and cool the combustible products within the flame zone. Meanwhile, the mixed metal oxide and char residue generated by the polymer/LDHs composite can protect the polymer from the air exposure and in turn suppress smoke production $[9,10]$. Furthermore, since the composition of the metal layers of LDHs can be varied, there are enormous potential applications as flame retardants [11]. Based on the above advantages of LDHs, we have paid significant attention to the design and preparation of LDHs as a non-halogenated additive of EVA [12-15]. 
A triazines derivative (CFA) containing hydroxylethylamino, triazine rings and ethylenediamine into groups was synthesized by our group [16]. It is used both as a charring agent and as a foaming agent in intumescent flame retardants (IFR) due to its excellent flame retardant properties and water resistance. To improve the flame retardance and thermal stability of polymer (polypropylene, EVA, polyethylene), CFA and ammonium polyphosphate (APP), systems with different synergistic agents (such as zinc borate, zeolites, organic montmorillonite) have been investigated in the previous report [17-22]. However, the research on the combination of LDHs and CFA/APP as synergistic flame retardants in EVA composites has never been reported. In the present work, a new composite flame retardant CFA/APP/LDHs was used in the ethylene vinyl acetate (EVA) matrix. Furthermore, the schematic of CFA/APP/LDHs and EVA was shown in Figure 1. The LOI, UL-94 and HRR results confirm that the synergistic flame retardant effects between CFA/APP and LDHs. The release yield and production rates of $\mathrm{CO}_{2}$ essentially mirror the HRR data. Moreover, the relationship between the $\mathrm{CO}_{2}$ and $\mathrm{CO}$ release is observed by the cone calorimeter test.

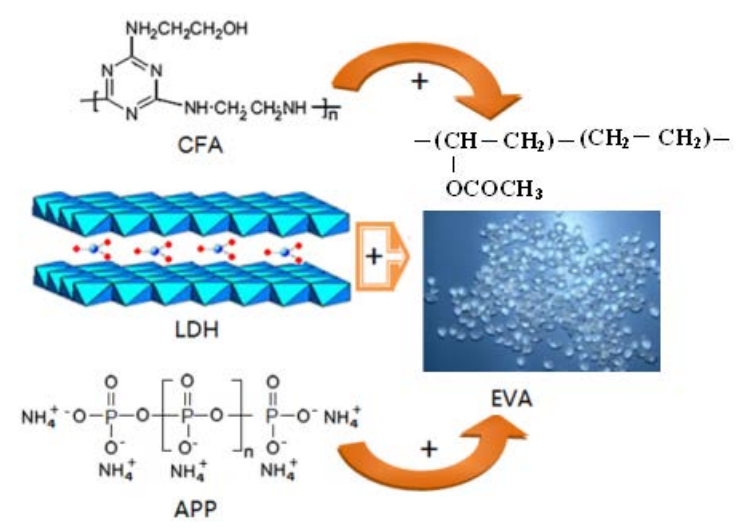

Figure 1. Schematic representation of CFA (charing-foaming agent)/APP (ammonium polyphosphate)/ LDHs (layered double hydroxides) and EVA (ethylene vinyl acetate).

\section{Materials and Methods}

\subsection{Materials}

All chemicals used in the preparation are analytical grade without further purification. Nickel nitrate (99\%), aluminum nitrate (99\%), magnesium nitrate $(99 \%)$, cobalt nitrate $(99 \%)$, copper nitrate $(99 \%)$, sodium stearate $(99 \%)$, sodium carbonate $(99 \%)$ and sodium hydroxide $(99 \%)$ were purchased from Tianjin Kemiou Fine Chemical Reagent Co. (Tianjin, China). EVA (VA-28\%) was offered from Samsung Co. (Seoul, Korea). Deionized water was made by a Milli-Q pure water apparatus in our Lab.

\subsection{Synthesis of the Modified-LDHs with $M^{2+}$ and $M^{3+}$ in a Molar Rate of 4:1}

A mixed aqueous solution containing transition metal nitrate, $\mathrm{Mg}\left(\mathrm{NO}_{3}\right)_{2}$ and $\mathrm{Al}\left(\mathrm{NO}_{3}\right)_{3}$ with a molar ratio of transition metal cations $\left(\mathrm{Ni}^{2+}\right.$ or $\mathrm{Co}^{2+}$ or $\left.\mathrm{Cu}^{2+}\right): \mathrm{Mg}^{2+}: \mathrm{Al}^{3+}$ of 0.05:3.95:1, was slowly added to $100 \mathrm{~mL}$ of deionized water at $70{ }^{\circ} \mathrm{C}$ with continuously magnetic stirring. In the synthesis, the $\mathrm{pH}$ value was adjusted to the range of 8 to 9 by adding the $\mathrm{NaOH}-\mathrm{Na}_{2} \mathrm{CO}_{3}$ mixed solution $\left(1.2 \mathrm{~mol} / \mathrm{L} \mathrm{NaOH}\right.$ and $\left.0.9 \mathrm{~mol} / \mathrm{L} \mathrm{Na}_{2} \mathrm{CO}_{3}\right)$. After the titration, a heavy suspension gel was obtained and then crystallized at $70{ }^{\circ} \mathrm{C}$ for $30 \mathrm{~min}$ in a microwave oven $(\mathrm{XH}-300 \mathrm{~A}$, the maximum power of $1000 \mathrm{~W}$ and a frequency of $2.45 \mathrm{GHz}$, Beijing Xianghu science and Technology Development Co. Beijing, China). The obtained precipitate was washed to $\mathrm{pH} 7$ by deionized water, and then filtered. The sample was then dried in an oven at $70{ }^{\circ} \mathrm{C}$ until a constant weight was achieved. The above synthesized precursor $10 \mathrm{~g}$ and $0.15 \mathrm{~g}$ stearate sodium were dispersed into $200 \mathrm{~mL}$ of deionized water. The mixture was crystallized at $70{ }^{\circ} \mathrm{C}$ for $30 \mathrm{~min}$ in a microwave oven. Then the precipitate was 
washed continuously with water to eliminate the excessive stearate sodium. The final $\mathrm{pH}$ was washed to 7 and then filtered. The resulting $\mathrm{LDHs}$ were named $\mathrm{LDH}-\mathrm{Ni}$, $\mathrm{LDH}-\mathrm{Co}$, and $\mathrm{LDH}-\mathrm{Cu}$, respectively.

\subsection{Preparation of Flame-Retarded EVA Composites}

A new IFR consists of APP, CFA and LDHs. The mass ratio of CFA to APP was fixed at 1:3. Simultaneously, the loading of IFR is kept at $20 \mathrm{wt} \%$ in the composite. All CFA/APP/LDH/EVA composites were melted and mixed in an RM-200A torque rheometer (Harbin University of Science and Technology, Haebin, China) with a rotor speed of $60 \mathrm{rpm}$ at $140{ }^{\circ} \mathrm{C}$ for $10 \mathrm{~min}$. The composites are named as ELDH-0, ELDH-Ni, ELDH-Co and ELDH-Cu, respectively. Table 1 shows the composition, limiting oxygen index (LOI) and vertical burning test (UL-94) data of the pure EVA and composites with $20 \mathrm{wt} \%$ of flame retardant.

Table 1. Composition, LOI and UL-94 test results for the pure EVA and composites.

\begin{tabular}{cccccccc}
\hline Sample Code & EVA (g) & APP (g) & CFA (g) & LDH (g) & LOI (\%) & $\begin{array}{c}\text { UL-94 Rating } \\
\text { (at 1.6 mm) }\end{array}$ & Phenomenon \\
\hline EVA & 180 & 0 & 0 & 0 & 18.0 & Fail & Dripping \\
ELDH0 & 144 & 27 & 9 & 0 & 28.5 & Fail & Dripping \\
ELDH-Ni & 144 & 24.6 & 8.2 & 3.2 & 30.3 & V-2 & Dripping \\
ELDH-Co & 144 & 24.6 & 8.2 & 3.2 & 29.7 & V-0 & No Dripping \\
ELDH-Cu & 144 & 24.6 & 8.2 & 3.2 & 30.8 & V-2 & Dripping \\
\hline
\end{tabular}

LOI: limiting oxygen index; UL-94: vertical burning test; EVA: ethylene vinyl acetate: APP: ammonium polyphosphate; CFA: charing-foaming agent; LDH: layered double hydroxides; ELDH: composite containing different $\mathrm{LDH}$.

\subsection{Measurements}

X-ray diffraction (XRD) was characterized using a D/MAX 2200 diffractometer (Rigaku, Tokyo, Japan) with $\lambda=1.5406 \AA$. Data were collected at the rate of $4^{\circ} / \mathrm{min}$ and step $0.02^{\circ}$ with $\mathrm{Cu} \mathrm{K} \alpha$ irradiation operated at $40 \mathrm{kV}$ and $45 \mathrm{~mA}$. Fourier transform infrared spectra (FTIR) were collected using a Nicolet FTIR360 spectrometer (Thermo Nicolet, Madison, WI, USA) (KBr pellet method, $4 \mathrm{~cm}^{-1}$ resolution, number of scans is 32 times). Scanning electron microscope (SEM) (FEI, Eindhoven, Holland) observations were carried out on a FEI-Sirion with a field emission of $20 \mathrm{kV}$. Thermal analysis was carried out with a thermogravimetric analyzer (TGA pyris 1 from Perkin Elmer, Perkin Elmer Co., Walther M, MA, USA) using a constant heating rate of $10^{\circ} \mathrm{C} / \mathrm{min}$ under the pure nitrogen atmosphere from 50 to $800{ }^{\circ} \mathrm{C}$. The weight of the samples was kept within 3-4 mg. All cone calorimeter tests were carried out in a cone calorimeter (FTT0007, Hongkong Universal Technology Co., Hongkong, China) at an incident heat flux of $50 \mathrm{~kW} / \mathrm{m}^{2}$ according to the ISO 5660-1 standard. The polymer sample $\left(100 \times 100 \times 5 \mathrm{~mm}^{3}\right)$ is placed horizontally on a balance holder.

\section{Results and Discussion}

\subsection{XRD and IR Analysis of the Prepared LDHs}

Figure 2A shows the XRD patterns of three LDHs. All patterns exhibit (003), (006), (012), (015), (018), (110) and (113) characteristic reflections of the LDHs structure, which can be indexed in a 3R polytype [23,24]. The basal spacing $\left(d_{\text {basal }}\right)$ of $\mathrm{LDH}-\mathrm{Ni}, \mathrm{LDH}-\mathrm{Co}$ and $\mathrm{LDH}-\mathrm{Cu}$ is $7.67,7.56$ and $7.67 \AA$, respectively. The thickness of a brucite-like layer is $4.8 \AA$ [25], the interlayer spacing of stearate and nitrate are approximately $26.72 \AA$ [26] and $4.23 \AA$ [27], respectively. Therefore, the $d_{\text {basal }}$ values of $\mathrm{LDH}-\mathrm{Ni}, \mathrm{LDH}-\mathrm{Co}$, and $\mathrm{LDH}-\mathrm{Cu}$ indicate that the interlayer anions are $\mathrm{CO}_{3}{ }^{2-}$, without the coexistence of $\mathrm{NO}_{3}{ }^{-}$or $\mathrm{C}_{18} \mathrm{H}_{35} \mathrm{O}_{2}{ }^{-}$. Figure $2 \mathrm{~B}$ gives the IR spectra of three LDHs. The bands at $3445 \mathrm{~cm}^{-1}$ and $1630 \mathrm{~cm}^{-1}$ are attributed to the $\mathrm{O}-\mathrm{H}$ stretching vibrations of layer hydroxyl groups and interlayer water molecules, respectively [28]. The band at $451 \mathrm{~cm}^{-1}$ is ascribed to deformation of $\mathrm{M}-\mathrm{OH}$ in the brucite-like layers. The band at $1376 \mathrm{~cm}^{-1}$ is assigned to the antisymmetric stretching mode $v_{3}$ of 
the interlayer carbonate. Two bands around $839 \mathrm{~cm}^{-1}$ and $680 \mathrm{~cm}^{-1}$ also are characteristic for the $v_{2}$ (out-of-plane deformation) and the $v_{2}$ (in-plane bending) of carbonate [29]. The IR analysis also confirms that the interlayer anions are only $\mathrm{CO}_{3}{ }^{2-}$ without the coexistence of $\mathrm{NO}_{3}{ }^{-}$(at $\left.1384 \mathrm{~cm}^{-1}\right)$. In addition, two bands at $2927 \mathrm{~cm}^{-1}$ and $2848 \mathrm{~cm}^{-1}$ are associated with the $\mathrm{C}-\mathrm{H}$ stretching vibrations of stearate anions. The weak bands at $1768 \mathrm{~cm}^{-1}$ are the $\mathrm{C}=\mathrm{O}$ vibrations of stearate anions $[30,31]$. These weak bands confirmed that the H-bonding interaction occurred between the carboxyl and the hydroxyl [32]. The combination of IR and XRD characterization indicates that the stearate was grafted on the surface of LDHs.
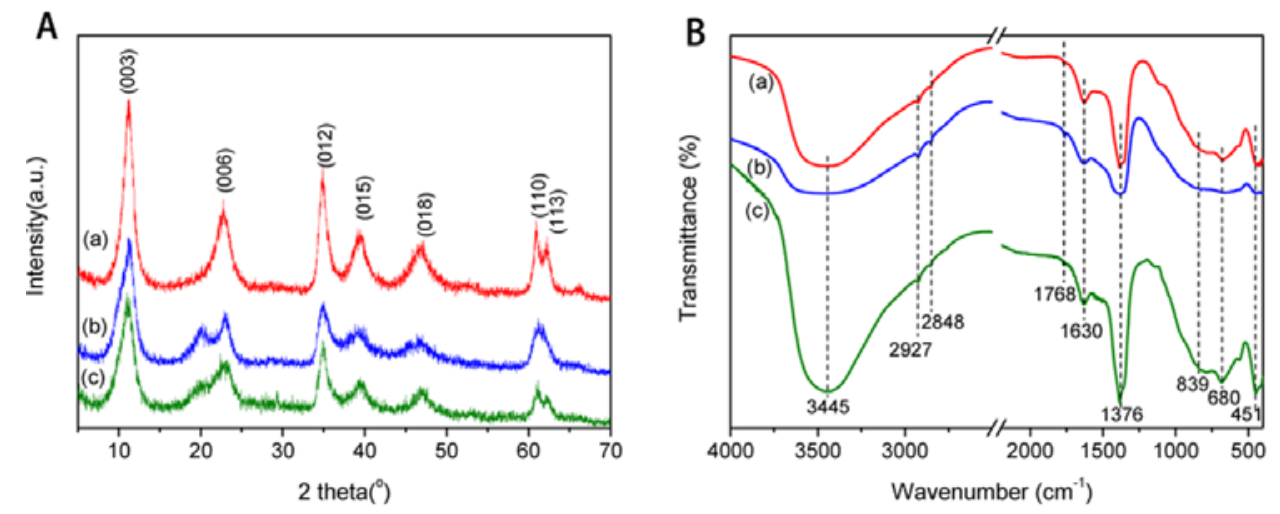

Figure 2. (A): XRD pattern; (B) IR spectrum of LDHs. (a) LDH-Ni; (b) LDH-Co; (c) LDH-Cu.

\subsection{Thermal Analysis of the Prepared LDHs and Composites.}

Figure 3 illustrates the TGA and DTG curves of three LDHs. The first stage corresponds to the mass losses of physical absorbed water and interlayer water. The mass losses of LDH-Ni, LDH-Co, and LDH-Cu are $14.8 \%, 15.3 \%$ and $15.6 \%$ in the TGA curves $\left(30-200{ }^{\circ} \mathrm{C}\right)$, respectively. The second stage is associated with the dehydroxylation of the metal hydroxide layers, the degradation of carbonates and stearate at a higher temperature interval $\left(200-800^{\circ} \mathrm{C}\right)$. Furthermore, the maximum mass loss rate temperatures of hydroxyls and carbonates are at 315 and $349^{\circ} \mathrm{C}$ for LDH-Ni and LDH-Co, respectively. In addition, the maximum mass loss rate temperatures of the stearate, residual hydroxyls and carbonates are at 375, 375 and $339^{\circ} \mathrm{C}$ for LDH-Ni, LDH-Co and LDH-Cu in the DTG curves, respectively.

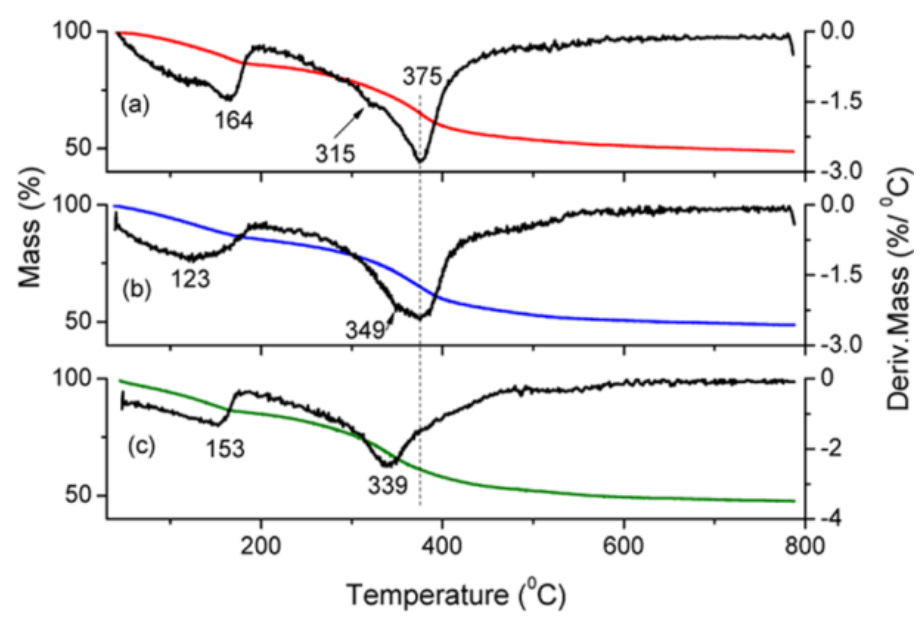

Figure 3. TGA-DTG curves of LDHs, (a) LDH-Ni; (b) LDH-Co; (c) LDH-Cu. 
Figure 4a,b illustrate the TGA and DTG curves of EVA and its composites with $20 \mathrm{wt} \%$ loading of flame retardants, respectively. The TGA curve of EVA showed two main mass loss steps with two mass loss rate maximums at about $353^{\circ} \mathrm{C}$ and $433^{\circ} \mathrm{C}$ in the DTG. The first step is attributed to the deacetylation of acetate side groups. The second step is due to the chain scission of ethylene leading to full thermal degradation at high temperatures [33,34]. From the DTG curves, it can be seen that, although the maximum mass loss rate temperature of the acetate side groups for all composites is almost the same as that of the pristine EVA at $353^{\circ} \mathrm{C}$, their maximum mass loss rate temperature of ethylene-based chains is higher than $433^{\circ} \mathrm{C}$ of the pristine EVA, for ELDH-Ni and ELDH-Co at $473{ }^{\circ} \mathrm{C}, \mathrm{ELDH}-0$ and ELDH-Cu at $470{ }^{\circ} \mathrm{C}$. The above thermal analysis results indicated that the flame retardants obviously enhanced the thermal degradation temperature of ethylene-based chains of the composites. The reason is that the flame retardants' released $\mathrm{H}_{2} \mathrm{O}, \mathrm{CO}_{2}, \mathrm{~N}_{2}$ and $\mathrm{NH}_{3}$ effectively delay the scission of ethylene-based chains. Furthermore, it can be seen that the maximal mass loss speed rate of ethylene-based chains for ELDH-Ni and ELDH-Cu is lower than the EVA, ELDH-Co and ELDH-0.
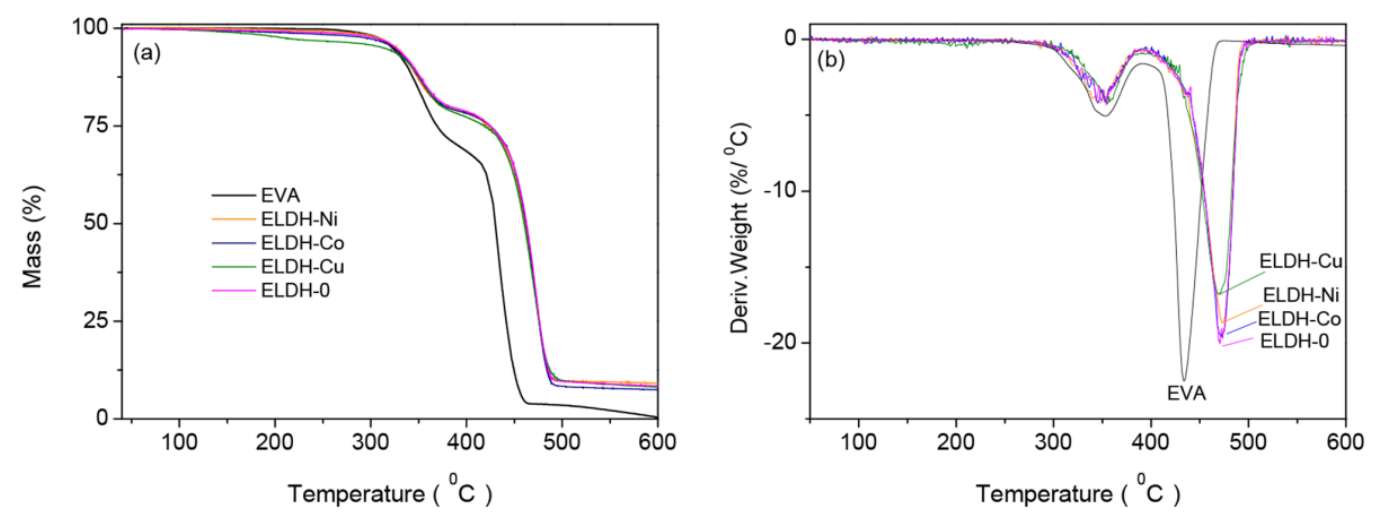

Figure 4. TGA-DTG curves of EVA and composites, (a) TGA curves; and (b) DTG curves.

\subsection{Flame Retardance and Smoke Suppression Mechanism of Composites}

From Table 1, it can be seen that the LOI value of ELDH-0, from $18 \%$ which is of the pure EVA, increases rapidly to $28.5 \%$. Then LOI values of ELDH-Ni, ELDH-Co and ELDH-Cu was increased to $30.3 \%, 29.7 \%$, and $30.8 \%$ due to the addition of LDHs. The LOI test indicates that the CFA/APP system and LDHs have significant synergistic flame retardant effects. The vertical burning (UL-94) test shows that ELDH-Ni, ELDH-Co, and ELDH-Cu reach UL-94 V-2, V-0 and V-2 ratings, respectively. However, ELDH-0 without a UL 94 rating was achieved due to the presence of melts dripping. The UL-94 result also confirms that the synergistic flame retardant effects between CFA/APP and LDHs.

To further identify the synergetic effects between LDHs and CFA/APP on the flame retardance and the smoke suppression behavior of composites, Figure 5 shows the heat release rate (HRR) curves of the pure EVA and composites by the cone calorimeter test. The HRR is considered to have a significant influence on fire hazards. Simultaneously, the peak value of HRR (pK-HRR) is used to assess the intensity of a fire. It can be seen that the pure EVA burned rapidly after ignition, and its pK-HRR value rises to $1120 \mathrm{~kW} / \mathrm{m}^{2}$. However, the pk-HRR values of ELDH-0, ELDH-Ni, ELDH-Co, and ELDH-Cu decrease to 258, 214, 231, and $206 \mathrm{~kW} / \mathrm{m}^{2}$, respectively. The reductions in pk-HRR for composites are 77\% greater than EVA. In particular, the reduction in pk-HRR of ELDH-Cu reaches $82 \%$. The HRR results also indicate that the flame retardant synergism was observed when LDHs are added into the composites with CFA/APP. 


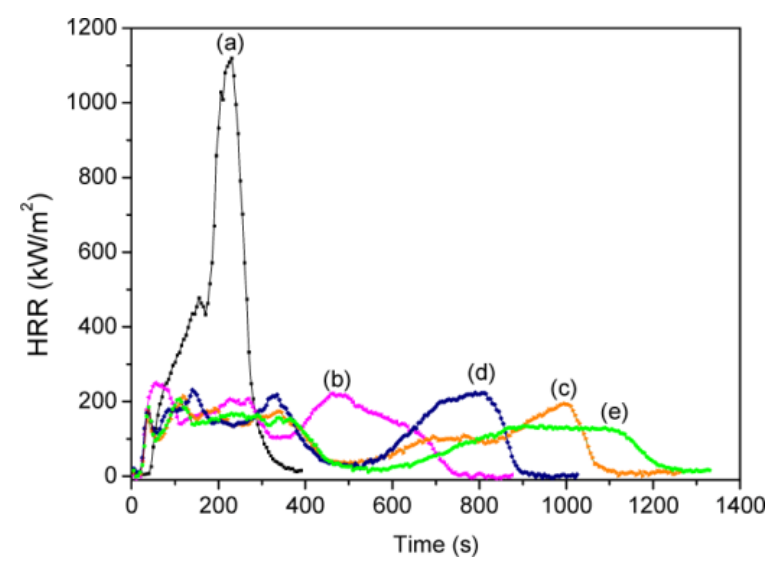

Figure 5. HRR (heat release rate) curves of the pure EVA and composites. (a) EVA; (b) ELDH-0; (c) ELDH-Ni; (d) ELDH-Co; and (e) ELDH-Cu.

For a long time, the char layer quality is considered to have an important influence on the flame retardance. Figure 6 shows the digital photographs of the residues after cone calorimeter tests. The residue of ELDH-0 has some holes. The residues of ELDH-Ni, ELDH-Co, and ELDH-Cu are not only thin, but also broken into several big pieces. To exhibit the internal morphology of the char residue, the SEM images, after cone calorimeter tests, are shown in Figure 7. The internal residue morphologies of four composites are obviously different. The residue of ELDH-Ni has a smooth structure with some holes of different sizes. The residues of ELDH-Co have many pores. These pores prevented melt dripping of ELDH-Co during combustion. The residues of ELDH-Cu and ELDH-0 have a compact morphology. All of the residues have no intumescent char layer, but metal oxide, char and APP promote charring via the cross-linking of reactive EVA fragments impeding the burning process by reducing the oxygen supply to the bulk phase [35].

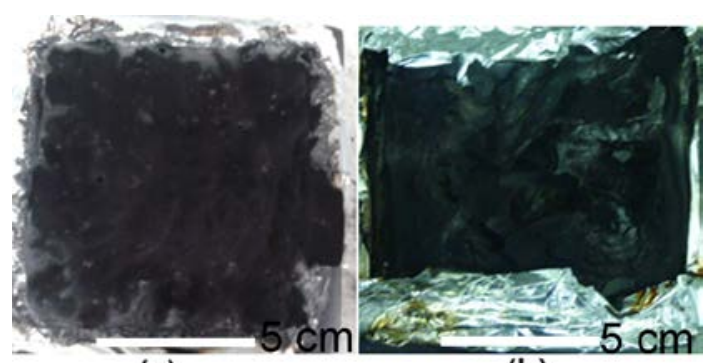

(a)

(b)

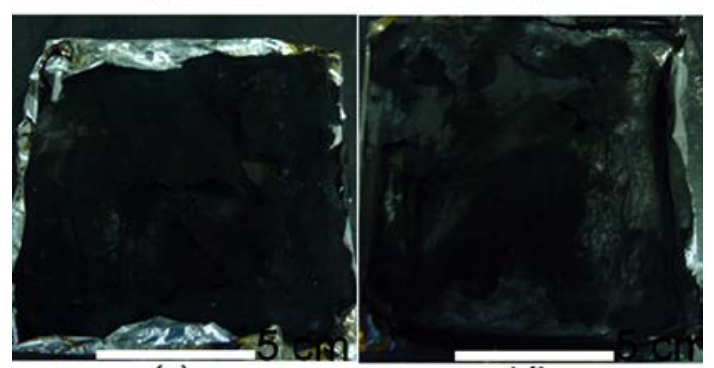

(c)

(d)

Figure 6. Digital photographs of the residues after cone calorimeter tests. (a) ELDH-0; (b) ELDH-Ni; (c) ELDH-Co; (d) ELDH-Cu. 


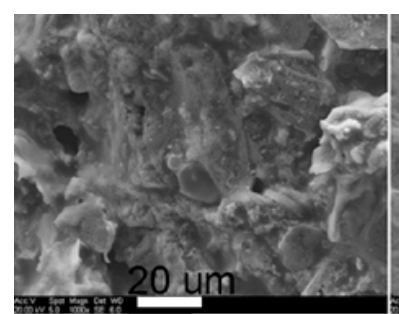

(a)

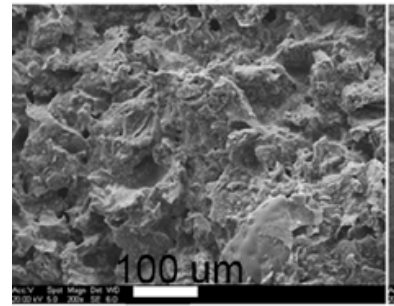

$\left(a^{\prime}\right)$

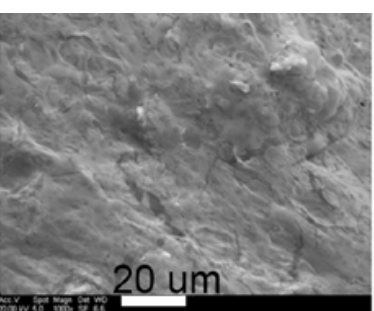

(b)

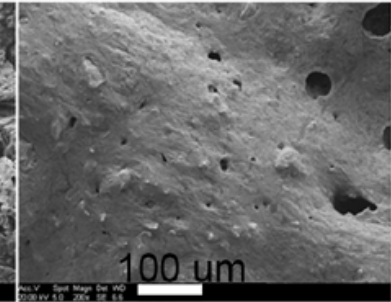

$\left(b^{\prime}\right)$

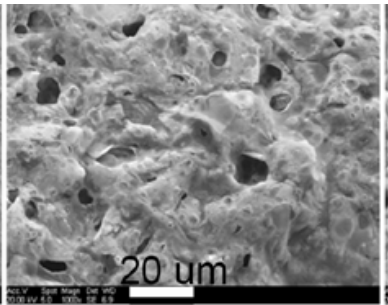

(c)

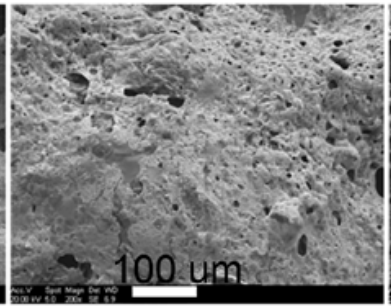

$\left(c^{\prime}\right)$

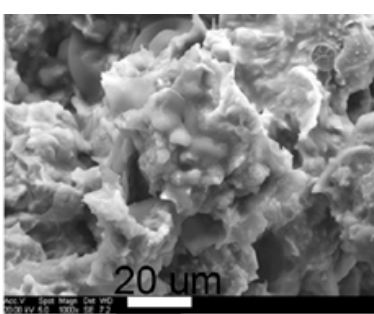

(d)

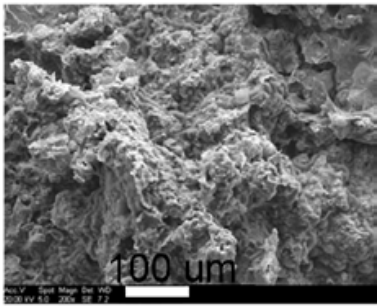

$\left(d^{\prime}\right)$

Figure 7. SEM images with $1000 \times((\mathbf{a}-\mathbf{d}))$ and $200 \times\left(\left(\mathbf{a}^{\prime}-\mathbf{d}^{\prime}\right)\right)$ of the residues after cone calorimeter

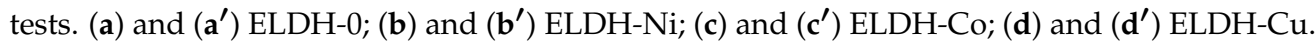

The mechanism of the synergistic effects between APP, CFA and LDHs can be included in the following. The formation of carbonized barrier prevents or slows the transfer of heat, oxygen, and combustible volatiles into the pyrolysis zone, retarding the combustion process [35]. APP decomposes at $200-250{ }^{\circ} \mathrm{C}$, it releases nonflammable gas such as $\mathrm{N}_{2}$ and $\mathrm{NH}_{3}$ to dilute the oxygen [36]. CFA decomposes at 319-450 ${ }^{\circ} \mathrm{C}$, it releases $\mathrm{H}_{2} \mathrm{O}$ and $\mathrm{NH}_{3}$ [16]. LDHs decompose to form $\mathrm{H}_{2} \mathrm{O}$ and $\mathrm{CO}_{2}$, which could dilute the flammable gases and oxygen, and decrease the temperature [35]. Therefore, the pk-HRR values of composites are obviously lower than pure EVA. Furthermore, the LDH-Cu has a lower maximum mass loss rate temperature of hydroxyls, carbonates and stearate than $\mathrm{LDH}-\mathrm{Ni}$ and $\mathrm{LDH}-\mathrm{Co}$. The consequent $\mathrm{LDH}-\mathrm{Cu}$ generated $\mathrm{H}_{2} \mathrm{O}$ and $\mathrm{CO}_{2}$ can cool, dilute and isolate oxygen during combustion early and rapidly. Thus, the LDH-Cu shows the better flame retardance among composites.

To verify the effect of $\mathrm{CO}_{2}$, Figure 8 shows the production rate of $\mathrm{CO}_{2}\left(\mathrm{CO}_{2} \mathrm{P}\right)$ curves of EVA and composites. A crucial relationship between HRR and $\mathrm{CO}_{2} \mathrm{P}$ was obtained. The shapes of $\mathrm{CO}_{2} \mathrm{P}$ curves are consistent with the HRR curves. The peak values of $\mathrm{CO}_{2} \mathrm{P}\left(\mathrm{pk}-\mathrm{CO}_{2} \mathrm{P}\right)$ time of the pure EVA, ELDH-0, ELDH-Ni, ELDH-Co, and ELDH-Cu are 235, 67, 125, 145 and $112 \mathrm{~s}$, respectively. The above pk- $\mathrm{CO}_{2} \mathrm{P}$ times are same as the pk-HRR time. The result indicates that when the production rate of $\mathrm{CO}_{2}$ reaches to the $\mathrm{pk}-\mathrm{CO}_{2} \mathrm{P}$ values, the HRR of samples reaches the pk-HRR values. Additionally, from the cone calorimeter test data, one can know that the $\mathrm{MCO}_{2} \mathrm{Y}$ is the mean release yield of $\mathrm{CO}_{2}$ of burning materials. The $\mathrm{MCO}_{2} \mathrm{Y}$ values of EVA, ELDH-0, ELDH-Ni, ELDH-Co and ELDH-Cu are $2.315,2.408,2.857,2.638$ and $2.834 \mathrm{~kg} / \mathrm{kg}$, respectively. The $\mathrm{MCO}_{2} \mathrm{Y}$ values of composites significantly increase because of the addition of LDHs. ELDH-Ni, ELDH-Co and ELDH-Cu release more $\mathrm{CO}_{2}$, which dilutes the flammable gases during combustion. Therefore, the composites with LDHs show reduced pk-HRR values compared to pure EVA and ELDH-0. This finding confirmed that the release yield and production rates of $\mathrm{CO}_{2}$ essentially mirror the HRR data [2]. 


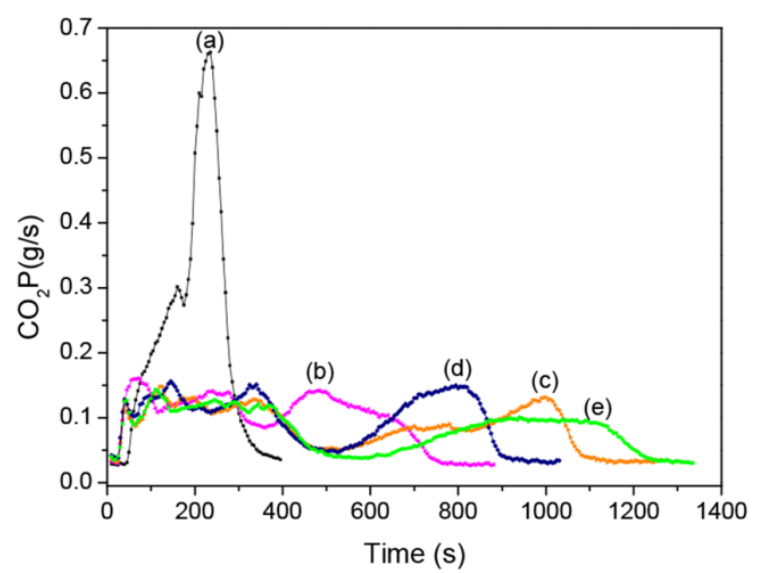

Figure 8. Production rate of $\mathrm{CO}_{2}\left(\mathrm{CO}_{2} \mathrm{P}\right)$ curves of EVA and composites. (a) EVA; (b) ELDH-0; (c) ELDH-Ni; (d) ELDH-Co; and (e) ELDH-Cu.

It is well known that most injuries and deaths result from the smoke and toxic gases in the case of fire [37]. From Figure 9A, it can be seen that the peak values of smoke production rate (pk-SPR) of ELDH-0, ELDH-Ni, ELDH-Co and ELDH-Cu are 0.053, 0.054, 0.057 and $0.036 \mathrm{~m}^{2} / \mathrm{s}$, respectively. These values are significantly lower than that of EVA $\left(0.109 \mathrm{~m}^{2} / \mathrm{s}\right)$. Moreover, the pk-SPR time of ELDH-Ni and ELDH-Co are extended to 994 and 793 s, respectively. They are much longer than the $89 \mathrm{~s}$ of ELDH- 0 and $251 \mathrm{~s}$ of EVA. Moreover, Figure 9B shows the production rate of $\mathrm{CO}$ (COP) curves of EVA and composites. The COP curves of all composites are significantly declined compared with EVA. The peak values of COP (pk-COP) for ELDH-Ni, ELDH-Co and ELDH-Cu are 0.0022, 0.0026, and $0.0025 \mathrm{~g} / \mathrm{s}$, respectively. They are obviously smaller than $0.0038 \mathrm{~g} / \mathrm{s}$ of ELDH- 0 and $0.0128 \mathrm{~g} / \mathrm{s}$ of EVA. Simultaneously, MCOY is the mean release yield of $\mathrm{CO}$ of burning materials. The MCOY value of EVA is $0.031 \mathrm{~kg} / \mathrm{kg}$, while the MCOY values of ELDH-0, ELDH-Ni, ELDH-Co and ELDH-Cu decrease to $0.0234,0.00765,0.0194$ and $0.0102 \mathrm{~kg} / \mathrm{kg}$, respectively. MCOY values of composites show an evident decrease compared with EVA. In particular, ELDH-Ni has the smallest MCOY value among composites. The extension of pk-SPR time, the reduction of pk-SPR, pk-COP and MCOY for composites are important contributions to people's evacuation and the rescue of firefighters. At the same time, the relationship between the $\mathrm{CO}_{2}$ and $\mathrm{CO}$ release is observed by the cone calorimeter test. When the $\mathrm{MCO}_{2} \mathrm{Y}$ is increased, the pk-COP and MCOY values are decreased. That is, the change tendency of the $\mathrm{MCO}_{2} \mathrm{Y}$ values is precisely opposite to the change tendency of pk-COP and MCOY values for EVA and composites.
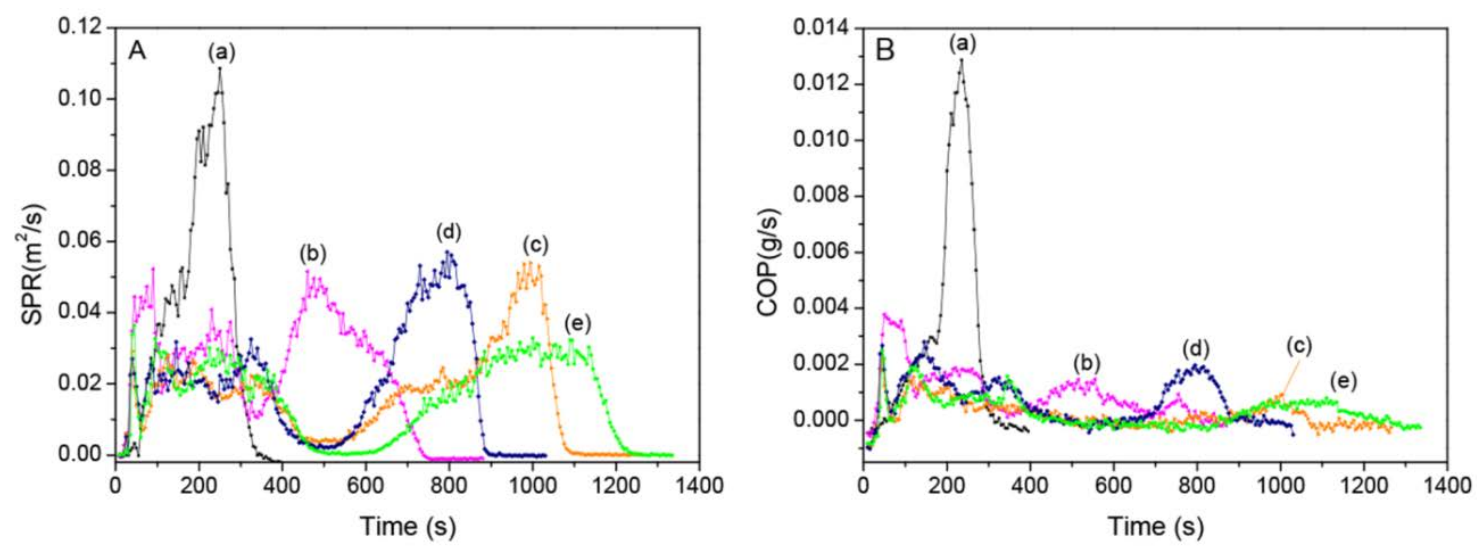

Figure 9. (A) Smoke production rate (SPR); and (B) production rate of CO (COP) curves of EVA and composites. (a) EVA; (b) ELDH-0; (c) ELDH-Ni; (d) ELDH-Co; and (e) ELDH-Cu. 


\section{Conclusions}

A novel IFR system consisting of CFA, APP, and LDHs was used in the EVA composites. The many pores of ELDH-Co residues prevented melt dripping of ELDH-Co. For LDH-Cu composite, the generated $\mathrm{H}_{2} \mathrm{O}$ and $\mathrm{CO}_{2}$ can cool, dilute and isolate oxygen early and rapidly during combustion. The LOI, UL-94 and HRR results confirm the synergistic flame retardant effects between CFA/APP and LDHs. Simultaneously, the change tendency of the $\mathrm{MCO}_{2} \mathrm{Y}$ values is precisely opposite to the pk-COP and MCOY values. The composite ELDH-Ni has the smallest pk-COP and MCOY value, while LDH-Cu has the best HRR, LOI and SPR values among all of the composites. This work not only confirms the flame retardance and smoke suppression mechanism of CFA/APP/LDHs/EVA composite, but also contributes to safety, the environment, and public health.

Acknowledgments: This study was financially supported by the Fundamental Research Funds for the Central Universities (No. 2572014CB29), the National Natural Science Foundation of China (No. 21304014 and No. 21376048).

Author Contributions: The author Lili Wang and Miaojun Xu contributed research and experimental work in this study. The authors Baoli Shi and Bin Li contributed data analysis work and revision of this paper.

Conflicts of Interest: The authors declare no conflict of interest.

\section{References}

1. Kalali, E.N.; Juan, S.D.; Wang, X.; Nie, S.; Wang, R.; Wang, D.Y. Comparative study on synergistic effect of LDH and zirconium phosphate with aluminum trihydroxide on flame retardancy of EVA composites. J. Therm. Anal. Calorim. 2015, 121, 619-626. [CrossRef]

2. Jiao, C.; Chen, X. Synergistic effects of titanium dioxide with layered double hydroxides in EVA/LDH composites. Polym. Eng. Sci. 2011, 51, 2166-2170. [CrossRef]

3. Liu, L.; Hu, J.; Zhuo, J.; Jiao, C.; Chen, X.; Li, S. Synergistic flame retardant effects between hollow glass microspheres and magnesium hydroxide in ethylene-vinyl acetate composites. Polym. Degrad. Stab. 2014, 104, 87-94. [CrossRef]

4. Batistella, M.; Otazaghine, B.; Sonnier, R.; Caro-Bretelle, A.-S.; Petter, C.; Lopez-Cuesta, J.-M. Fire retardancy of ethylene vinyl acetate/ultrafine kaolinite composites. Polym. Degrad. Stab. 2014, 100, 54-62. [CrossRef]

5. Altarawneh, M.; Dlugogorski, B.Z. Thermal Decomposition of 1,2-Bis(2,4,6-tribromophenoxy)ethane (BTBPE), a novel brominated flame retardant. Environ. Sci. Technol. 2014, 48, 14335-14343. [CrossRef] [PubMed]

6. Altarawneh, M.; Dlugogorski, B.Z. Mechanism of thermal decomposition of tetrabromobisphenol a (TBBA). J. Phys. Chem. A 2014, 118, 9338-9346. [CrossRef] [PubMed]

7. Zhang, M.; Yao, Q.; Lu, C.; Li, Z.; Wang, W. Layered double hydroxide-carbon dot composite: High-performance adsorbent for removal of anionic organic dye. ACS Appl. Mater. Interfaces 2014, 6, 20225-20233. [CrossRef] [PubMed]

8. Sahoo, P.; Ishihara, S.; Yamada, K.; Deguchi, K.; Ohki, S.; Tansho, M.; Shimizu, T.; Eisaku, N.; Sasai, R.; Labuta, J.; et al. Rapid exchange between atmospheric $\mathrm{CO}_{2}$ and carbonate anion intercalated within magnesium rich layered double hydroxide. ACS Appl. Mater. Interfaces 2014, 6, 18352-18359. [CrossRef] [PubMed]

9. Wang, B.; Zhou, K.; Wang, B.; Gui, Z.; Hu, Y. Synthesis and characterization of $\mathrm{CuMoO}_{4} / \mathrm{Zn}-\mathrm{Al}$ layered double hydroxide hybrids and their application as a reinforcement in polypropylene. Ind. Eng. Chem. Res. 2014, 53, 12355-12362. [CrossRef]

10. Gao, Y.; Wang, Q.; Wang, J.; Huang, L.; Yan, X.; Zhang, X.; He, Q.; Xing, Z.; Guo, Z. Synthesis of highly efficient flame retardant high-density polyethylene nanocomposites with inorgano-layered double hydroxides as nanofiller using solvent mixing method. ACS Appl. Mater. Interfaces 2014, 6, 5094-5104. [CrossRef] [PubMed]

11. Li, Y.C.; Yang, Y.H.; Shields, J.R.; Davis, R.D. Layered double hydroxide-based fire resistant coatings for flexible polyurethane foam. Polymer 2015, 56, 284-292. [CrossRef]

12. Wang, L.; Li, B.; Hu, Z.; Cao, J. Effect of nickel on the properties of composites composed of layered double hydroxides and ethylene vinyl acetate copolymer. Appl. Clay Sci. 2013, 72, 138-146. [CrossRef] 
13. Wang, L.; Li, B.; Zhang, X.; Chen, C.; Zhang, F. Effect of intercalated anions on the performance of Ni-Al LDH nanofiller of ethylene vinyl acetate composites. Appl. Clay Sci. 2012, 56, 110-119. [CrossRef]

14. Wang, L.; Li, B.; Zhao, X.; Chen, C.; Cao, J. Effect of rare earth ions on the properties of composites composed of ethylene vinyl acetate copolymer and layered double hydroxides. PLoS ONE 2012, 7, e37781. [CrossRef] [PubMed]

15. Wang, L.; Li, B.; Yang, M.; Chen, C.; Liu, Y. Effect of Ni cations and microwave hydrothermal treatment on the related properties of layered double hydroxide-ethylene vinyl acetate copolymer composites. J. Colloid Interface Sci. 2011, 356, 519-525. [CrossRef] [PubMed]

16. Li, B.; Xu, M. Effect of a novel charring-foaming agent on flame retardancy and thermal degradation of intumescent flame retardant polypropylene. Polym. Degrad. Stab. 2006, 91, 1380-1386. [CrossRef]

17. Ding, S.; Feng, J.; Hao, J.; Liao, Q. A study on the fire resistance performance and thermal degradation behavior of a new intumescent flame retardant fluoroelastomer. J. Fire Sci. 2014, 32, 362-373. [CrossRef]

18. Nie, S.; Qi, S.; He, M.; Li, B. Synergistic effects of zeolites on a novel intumescent flame-retardant low-density polyethylene (LDPE) system. J. Therm. Anal. Calorim. 2013, 114, 581-587. [CrossRef]

19. Li, S.; Li, B. Effect of elastomer on flame retardancy, thermal degradation, and mechanical properties of intumescent flame-retardant polyethylene. J. Elastom. Plast. 2011, 43, 257-273.

20. Nie, S.; Peng, C.; Yuan, S.; Zhang, M. Thermal and flame retardant properties of novel intumescent flame retardant polypropylene composites. J. Therm. Anal. Calorim. 2013, 113, 865-871. [CrossRef]

21. Bai, P.; Li, B.; Gao, S.; Lin, M.; Wang, M. Investigation on flame retardancy and antidripping of new intumescent flame retardant polypropylene film. Polym. Polym. Compos. 2010, 18, 495-502.

22. Li, B.; Jia, H.; Guan, L.; Bing, B.; Dai, J. A novel intumescent flame-retardant system for flame-retarded LLDPE/EVA composites. J. Appl. Polym. Sci. 2009, 114, 3626-3635. [CrossRef]

23. Herrero, M.; Benito, P.; Labajos, F.M.; Rives, V. Stabilization of $\mathrm{Co}^{2+}$ in layered double hydroxides (LDHs) by microwave-assisted ageing. J. Solid State Chem. 2007, 180, 873-884. [CrossRef]

24. Wang, B.; Williams, G.R.; Chang, Z.; Jiang, M.; Liu, J.; Lei, X.; Sun, X. Hierarchical NiAl layered double hydroxide/multiwalled carbon nanotube/nickel foam electrodes with excellent pseudocapacitive properties. ACS Appl. Mater. Interfaces 2014, 6, 16304-16311. [CrossRef] [PubMed]

25. Kwon, T.; Tsigdinos, G.A.; Pinnavaia, T.J. Pillaring of layered double hydroxides (LDH's) by polyoxometalate anions. J. Am. Chem. Soc. 1988, 110, 3653-3654. [CrossRef]

26. Wang, L.; Li, B.; Chen, C.; Jia, L. Structural characterization and related properties of the stearate anions intercalated $\mathrm{Ni}-\mathrm{Al}$ hydrotalcite-like compound prepared by the microwave crystallization. J. Alloys Compd. 2010, 508, 426-432. [CrossRef]

27. Prabir, K.D.; Micky, P. Anion exchange in lithium aluminate hydroxides. J. Phys. Chem. 1989, 93, $376-381$.

28. Nethravathi, C.; Viswanath, B.; Sebastian, M.; Rajamathi, M. Exfoliation of $\alpha$-hydroxides of nickel and cobalt in water. J. Colloid Interface Sci. 2010, 345, 109-115. [CrossRef] [PubMed]

29. Violante, A.; Pucci, M.; Cozzolino, V.; Zhu, J.; Pigna, M. Sorption/desorption of arsenate on/from Mg-Al layered double hydroxides: influence of phosphate. J. Colloid Interface Sci. 2009, 333, 63-70. [CrossRef] [PubMed]

30. Mallakpour, S.; Dinari, M. Facile synthesis of nanocomposite materials by intercalating an optically active poly(amide-imide) enclosing (l)-isoleucine moieties and azobenzene side groups into a chiral layered double hydroxide. Polymer 2013, 54, 2907-2916. [CrossRef]

31. Guan, Y.; Wang, C.; Wang, D.; Dang, G.; Chen, C.; Zhou, H.; Zhao, X. High transparent polyimides containing pyridine and biphenyl units:Synthesis, thermal, mechanical, crystal and optical properties. Polymer 2015, 62, 1-10. [CrossRef]

32. Marangoni, R.; Taviot-Guého, C.; Illaik, A.; Wypych, F.; Leroux, F. Organic inorganic dye filler for polymer: Blue-coloured layered double hydroxides into polystyrene. J. Colloid Interface Sci. 2008, 326, 366-373. [CrossRef] [PubMed]

33. Costache, M.C.; Jiang, D.D.; Wilkie, C.A. Thermal degradation of ethylene-vinyl acetate coplymer nanocomposites. Polymer 2005, 46, 6947-6958. [CrossRef]

34. Zhang, G.; Ding, P.; Zhang, M.; Qu, B. Synergistic effects of layered double hydroxide with hyperfine magnesium hydroxide in halogen-free flame retardant EVA/HFMH/LDH nanocomposites. Polym. Degrad. Stab. 2007, 92, 1715-1720. [CrossRef] 
35. Li, L.; Qian, Y.; Jiao, C. Synergistic flame retardant effects of ammonium polyphosphate in ethylene-vinyl acetate/layered double hydroxides composites. Polym. Eng. Sci. 2014, 54, 766-776. [CrossRef]

36. Hu, Y.C.; Wu, Z.P.; Sun, H.Z.; Zhou, Y.; Liu, Y. Synthesis and flame retardation of an ammonium polyphosphate. J. Funct. Mater. 2006, 37, 424-427.

37. Wang, L.; Zhang, M.; Li, B. Thermal analysis and flame-retarded mechanism of composites composed of ethylene vinyl acetate and layered double hydroxides containing transition metals ( $\mathrm{Mn}, \mathrm{Co}, \mathrm{Cu}, \mathrm{Zn}$ ). Appl. Sci. 2016, 6, 131. [CrossRef]

(c) 2016 by the authors; licensee MDPI, Basel, Switzerland. This article is an open access article distributed under the terms and conditions of the Creative Commons Attribution (CC-BY) license (http:/ / creativecommons.org/licenses/by/4.0/). 